\title{
Colonic explosion during treatment of radiotherapy complications in prostatic cancer
}

\author{
STEFANO TRASTULLI $^{1}$, IVAN BARILLARO ${ }^{1}$, JACOPO DESIDERIO ${ }^{1}$, GIORGIO DI ROCCO ${ }^{2}$, \\ GIOVANNI COCHETTI $^{3}$, VALERIO MECARELLI ${ }^{1}$, ROBERTO CIROCCHI $^{1}$, ALBERTO SANTORO ${ }^{2}$, \\ CARLO BOSELLI $^{1}$, ADRIANO REDLER ${ }^{2}$, NICOLA AVENIA ${ }^{4}$ and GIUSEPPE NOYA ${ }^{1}$ \\ ${ }^{1}$ Department of General Surgery, University of Perugia, Perugia; \\ ${ }^{2}$ Department of Surgical Sciences, Sapienza University of Rome, Rome; ${ }^{3}$ Department of Surgical Specialties, Urological \\ Andrological Surgery and Minimally Invasive Techniques, University of Perugia, Terni; \\ ${ }^{4}$ Endocrine Surgical Unit, University of Perugia, Perugia, Italy
}

Received January 16, 2012; Accepted April 20, 2012

DOI: $10.3892 / \mathrm{ol} .2012 .873$

\begin{abstract}
The use of lasers has been of great importance in the field of endoscopy and surgery for their applications in coagulation and the ability to vaporize tissue. In the 1990s, new machines were introduced based on a different technology, the argon-plasma-coagulation (APC) system. This technology causes different biological effects without direct contact. An example is the hemostasis of bleeding. In the literature, several cases of complications have been reported during endoscopic treatment with APC. In this study, we report our experience of a case with colon explosion during an APC procedure for bleeding due to radiotherapy and also review the literature on the complications of APC treatment.
\end{abstract}

\section{Introduction}

Technological development has led, over time, to the introduction and use of new devices in medicine and surgery. Laser instruments (light amplification by stimulated emission of radiation) have emerged in clinical practice based on the effects of coherent and collimated monochromatic light radiation with high brightness on chromophores or optical baits that are normally present in biological tissues.

The use of lasers such as neodymium:yttrium-aluminumgarnet (Nd:YAG) initially have been of great importance in the field of endoscopy and surgery due to their applications in coagulation. Moreover, lasers have the ability to vaporize

Correspondence to: Dr Jacopo Desiderio, Department of General Surgery, University of Perugia, St. Maria Hospital, Via Tristano di Joannuccio, Terni 05100, Italy

E-mail: djdesi85@hotmail.it

Key words: argon-plasma-coagulation, laser, endoscopic, explosion, radiotherapy complication tissue with great penetrating capacity with the possibility of spreading into the interstice by flexible fibers of various sizes, shapes and sections, creating well-demarcated necrosis without significant damage to the adjacent structures (Fig. 1) (1-3).

From the early 1990s, however, new devices based on a different technology were introduced. In particular, in 1992 the argon-plasma-coagulation (APC) system was introduced in endoscopy (4). The APC allows, without direct contact, a high frequency monopolar current through a plasma gas (argon) (4). The biological effect of the high frequency carried by the plasma current to tissues is heating of the tissue that is capable of leading to different thermal effects: devitalization, coagulation, drying and contraction (Fig. 2) (5). In the literature, various possible endoscopic applications of this device have been reported.

APC has been used in endoscopic hemostatic treatment for bleeding from several different sources and at different levels (5), including in the treatment of refractory ulcerative recto-colitis (6), Barrett's esophagus (7), Dieulafoy's lesions (8), stenosis in colon malignant tumors (9), in radiation-induced proctitis (10), adenomas $(11,12)$ and angiodysplasia (13).

The APC platform for endoscopic applications is marketed in two models (Conmed, Utica, NY, USA; ERBE Electromedizin, Tubingen, Germany) and includes a monopolar frequency electrosurgical generator, a source of argon gas, a gas flow meter, flexible catheters, a pedal of activation and a petri dish to ground.

The probes consist of a Teflon tube coupled to a ceramic nozzle hosting a monopolar tungsten electrode (Fig. 2). The APC is widely used due to the easy application and lower rate of perforation compared to laser therapy, by virtue of tissue penetration of 1-3 mm. Nevertheless, the APC procedure is not risk-free. Rare complications cannot be excluded and are capable of resulting in major injuries and mortality (5).

With the increase in the number of possible applications and the volume of patients, possible common or unusual side effects have been reported in the literature. The most common 
symptoms are anorectal pain for localized treatment near the dentate line, meteorism and abdominal cramps with vagal signs of visceral distension (14).

The most frequent complications are perforations by penetration even in relatively infrequent loci (15), but cases of perforation by explosion have also been described (16). Manner et al (16) define explosion as a sudden release of energy that leads to a rapid increase in temperature and pressure. This event may occur when a mixture of explosive gases reaches a trigger temperature. Normally in the colon, hydrogen and methane are produced for the fermentation of non-absorbable (lactulose, mannitol) or partially absorbable (lactose, fructose, sorbitol) carbohydrates in the lumen of the colon by resident bacterial flora (16).

Therefore, to minimize the possible risks associated with a sudden release of energy, it is necessary to properly prepare the colon, forbidding the use of preparations containing these substances; however, enemas should be performed. It is also important to take particular caution in the vicinity of tight stenosis for the possible presence of gas pockets upstream of the stenosis itself, which could be released by the procedure. This report describes a case of colon explosion at a distance from the surgically treated area.

This study was approved by the ethics committee of the University of Perugia and of the Sapienza University of Rome. The patient provided written informed consent for permission to perform surgical and endoscopic procedures, to transfuse blood (in case of need), to inform relatives (wife and/or parents) about the patient clinical outcome and to use the data and/or pictures for scientific purpose.

\section{Case report}

In this study, we report a 73-year-old patient, who underwent emergency surgery for suspected colonic perforation following endoscopic treatment with APC. The patient, who had a history of hypertension and prostate cancer, underwent endoscopic coagulation using APC for rectal angiodysplasia and bleeding arising following radiotherapy performed for prostate cancer.

For this purpose the patient had an evacuative micro-enema without the addition of oral preparations. The operator of the endoscopy heard a thump during the execution of the procedure Therefore, the probe was immediately removed and an X-ray of the abdomen was performed that revealed signs of perforation.

The patient underwent surgery for acute abdomen with findings of fecal peritonitis of the pelvis and left iliac fossa by double-tearing of the colon sigmoid associated with mesosigmoid hematoma, vascular laceration and hemoperitoneum (Figs. 3 and 4). Resection of the bowel and the sinking of the rectum by stapler were performed. The colostomy was performed in the left iliac fossa, on the distal descending colon.

The hospital stay was complicated by two episodes: pulmonary edema with bilateral pleural effusion and atelectasis on the eighth day, as shown by CT scan, which was solved with medical therapy; a wound dehiscence that was treated with convac. The patient was discharged in good health on the 32nd day while waiting for recanalization.
A

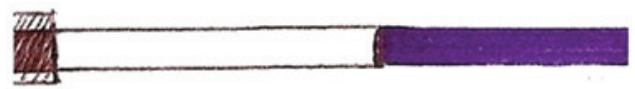

B

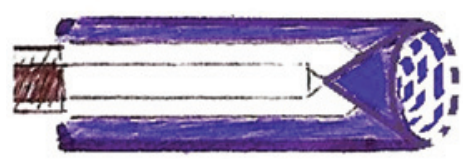

C

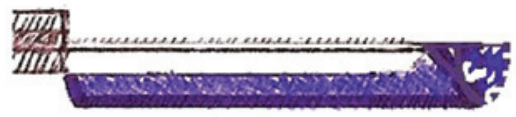

D

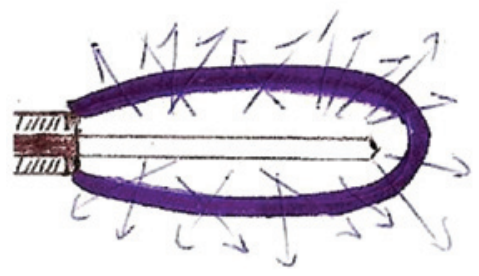

Figure 1. (A) Irradiation characteristics of different laser fibers for Nd:YAG: exposed fiber. (B) Circular and (C) semicircular irradiation fibers and (D) diffuse irradiation fibers are shown.

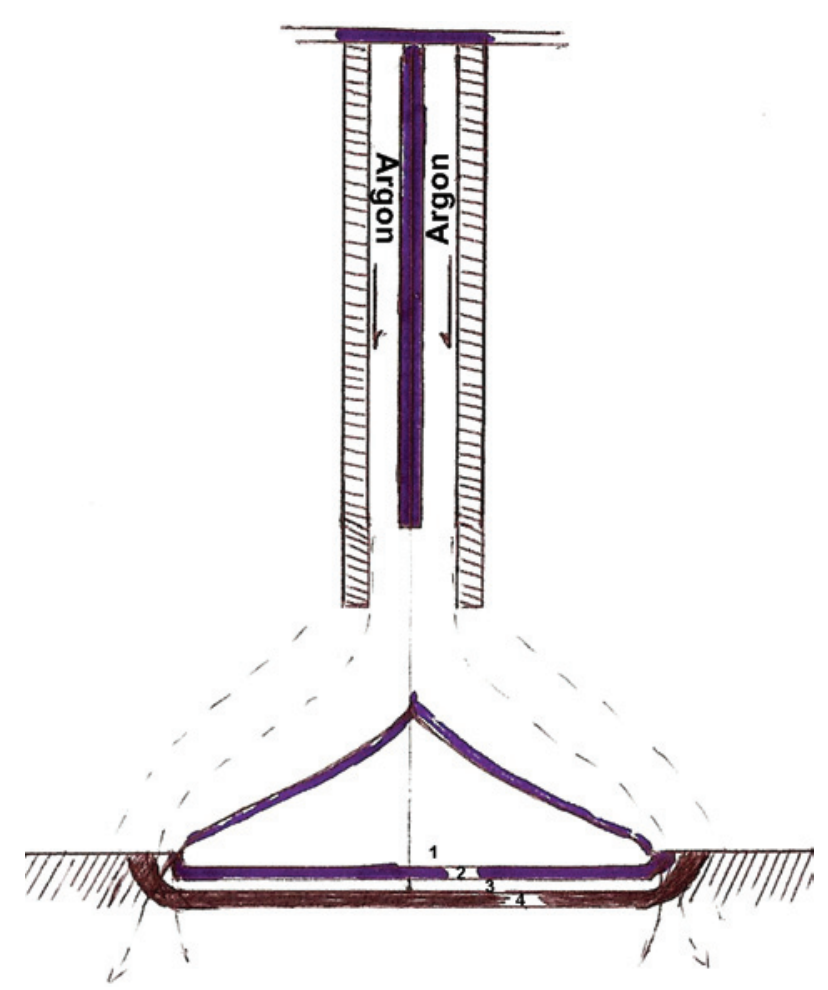

Figure 2. Diagram of the effects of HF current on biological tissues: 1 , devitalization; 2 , coagulation; 3 , drying; 4 , contraction.

\section{Discussion}

In the literature, during the last decade, several cases of colonic explosions during APC procedures have been reported. Such 
Table I. Overview of cases of colonic explosion during treatment with APC.

\begin{tabular}{|c|c|c|c|c|c|}
\hline Year & No. & Author & Diagnosis & Preparation & Complication \\
\hline 1999 & 1 & Zinsser et al (9) & $\begin{array}{l}\text { Neoplastic stenosis of the } \\
\text { recto-sigmoid junction }\end{array}$ & Enema & Explosion without perforation \\
\hline 2004 & 1 & Pichon et al (12) & $\begin{array}{l}\text { Adenoma of the sigmoid } \\
\text { colon }\end{array}$ & Enema & 3 perforated lesions of sigmoid \\
\hline 2004 & 3 & Ben-Soussan et al (10) & Radiation proctitis & Enema & 1 perforation \\
\hline 2007 & 1 & Townshend et al (11) & $\begin{array}{l}\text { Adenoma of rectum with } \\
\text { bleeding }\end{array}$ & Enema & $\begin{array}{l}\text { Explosion of sigma with laceration, } \\
\text { Hartmann intervention }\end{array}$ \\
\hline 2007 & 1 & Nurnberg et al (13) & $\begin{array}{l}\text { Angiodysplasia of right } \\
\text { colon }\end{array}$ & Macrogol solution & $\begin{array}{l}2 \text { perforations of cecum and } \\
\text { ascending colon, right hemicolectomy }\end{array}$ \\
\hline 2010 & 1 & $\begin{array}{l}\text { Trastulli et al } \\
\text { (Present study) }\end{array}$ & $\begin{array}{l}\text { Angiodysplasia of the } \\
\text { rectum due to radiation }\end{array}$ & Mini enema & $\begin{array}{l}\text { Explosion of sigma with laceration, } \\
\text { Hartmann intervention }\end{array}$ \\
\hline
\end{tabular}

APC, argon-plasma-coagulation.

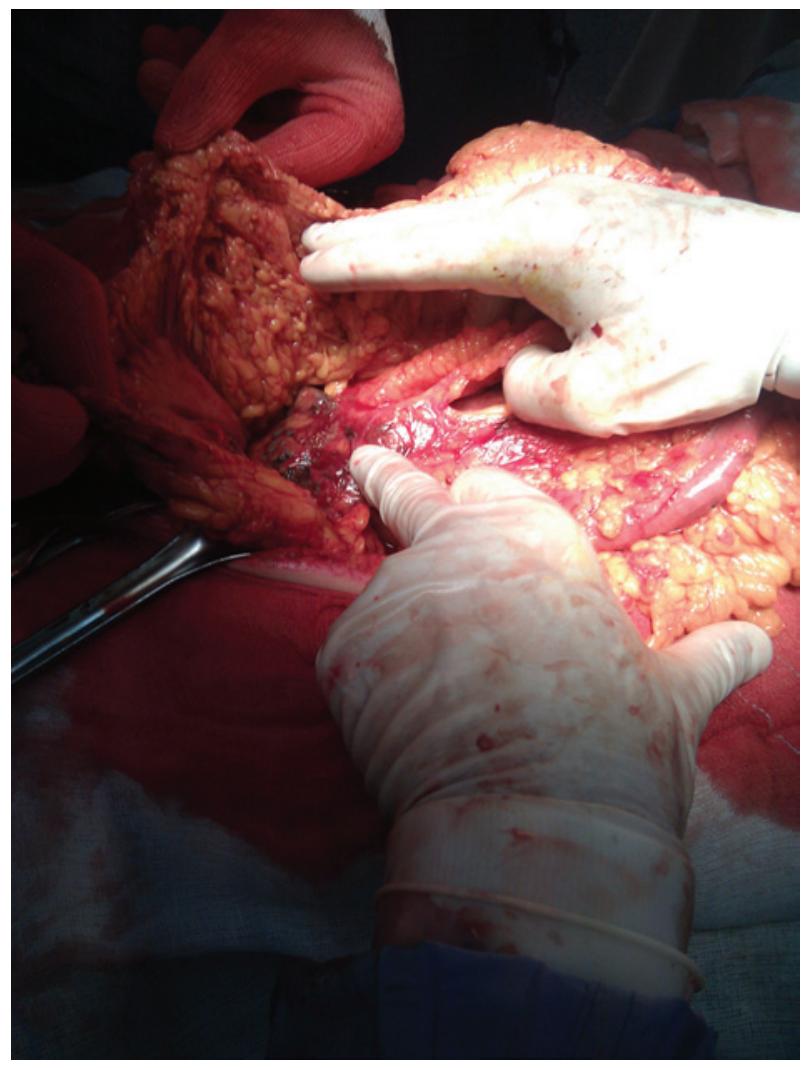

Figure 3. Mesosigma hematoma with lacerations.

cases were observed in the treatment of stenosis of the colon, adenomas, angiodysplasia and proctitis caused by radiation (Table I). The incidence has been significantly higher in those cases where the colon was prepared locally than in those where oral preparations occurred $(9,11,12)$.

Ben-Soussan et al treated 27 patients with APC for radiation-induced hemorrhagic proctitis. Prior to treatment with APC, the colon was prepared with enema polyethylene glycol or sodium phosphate. During treatment, in two patients there

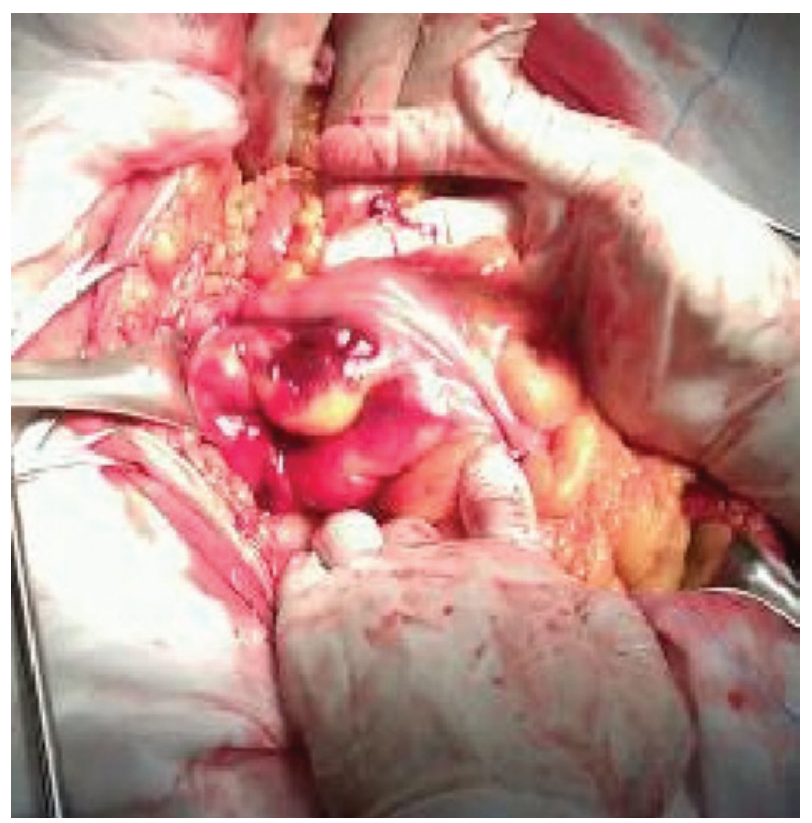

Figure 4. Mesosigma hematoma with lacerations.

were three explosions of the colon. The first patient experienced two explosions in succession. The second patient had an explosion that led to an immediate perforation of an area away from that treated endoscopically (10).

In 2007, Nurnberg et al reported a case of a 69-year-old patient with an explosion of the colon during treatment with APC. In contrast to the literature, in this case the patient was prepared with Macrogol solution (13). This was the first case described in the literature of a perforated colon during endoscopic treatment with APC in a patient prepared with Macrogol solution.

The following adverse events may be the trigger for explosive gas mixtures (16): The use of oral preparations that may lead to fermentation (13); or simple enemas to evacuate the large bowel, but without oral preparation (10). To date, there is no consensus 
on the guidelines for the intestinal preparation before APC, also in regards of drugs for oral preparation (17). In our case, the preparation was further reduced and although the endoscopist worked in the lower rectum, with the reasonable assumption of the absence of pockets of gas, there was, however, a distant explosion, which led to serious injury and risk to the life of the patient.

Subsequently, it appears that the risk of explosion with this method is real even for minor endoscopic procedures, it may occur in the more distant colonic segments and it is clearly machine- or operator-independent. It depends only on the unpredictable amount of intestinal gases and their motion.

Therefore, it is desirable that proper preparation for colon cleansing both orally and through enemas occurs, as well as a reduction of meteorism by administering a proper diet to the patient in preparation for the procedure and the use of aids such as a rectal tube placed just before the procedure to drain any pockets of gas present in the colonic segments.

In case of explosion the injuries are extremely serious due to the association of peritonitis and hemoperitoneum, and the treatment should be limited to the minimum according to the theory of 'damage control surgery'.

\section{References}

1. Philipp C, Rohde E and Berlien HP: Nd:YAG laser procedures in tumor treatment. Semin Surg Oncol 11: 290-298, 1995.

2. Vogl TJ, Mack MG, Straub R, Roggan A and Felix R: Magnetic resonance imaging-guided abdominal interventional radiology: laser-induced thermotherapy of liver metastases. Endoscopy 29: 577-583, 1997.

3. Rohde E, Mesecke-von Rheinbaren I, Roggan A, Podbielska H, Hopf M and Muller G: Interstitial laser-induced thermotherapy (LITT): comparison of in-vitro irradiation effects of Nd:YAG (1064 nm) and diode (940 nm) laser. Med Laser Appl 16: 81-90, 2001.
4. Vargo JJ: Clinical applications of the argon plasma coagulator. Gastrointest Endosc 59: 81-88, 2004.

5. Grund KE, Straub T and Farin G: New haemostatic techniques: argon plasma coagulation. Baillieres Best Pract Res Clin Gastroenterol 13: 67-84, 1999.

6. Dumortier J, Scoazec JY and Ponchon T: Argon plasma coagulation therapy for refractory ulcerative colitis. Gastrointest Endosc 60: 317-319, 2004.

7. Bate JP and Schoeman MN: Argon plasma coagulation for Barrett's esophagus. Tech Gastrointest Endosc 12: 40-43, 2010.

8. Yarze JC: Argon plasma coagulation of Dieulafoy's lesions. Gastrointest Endosc 63: 733, 2006.

9. Zinsser E, Will U, Gottschalk P, et al: Bowel gas explosion during argon plasma coagulation. Endoscopy 31: S26, 1999.

10. Ben-Soussan E, Antonietti M, Savoye G, et al: Argon plasma coagulation in the treatment of hemorrhagic radiation proctitis is efficient but requires a perfect colonic cleansing to be safe. Eur J Gastroenterol Hepatol 16: 1315-1318, 2004.

11. Townshend AP, Goddard WP and Cid JA: Bowel perforation requiring emergency laparotomy and a Hartmann's procedure after a gas explosion induced by argon plasma coagulation. Endoscopy 39: E1, 2007.

12. Pichon N, Maisonnette F, Cessot F, et al: Colonic perforations after gas explosion induced by argon plasma coagulation. Endoscopy 36: 573, 2004.

13. Nurnberg D, Pannwitz H, Burkhardt KD, et al: Gas explosion caused by argon plasma coagulation of colonic angiodysplasias. Endoscopy 39: E182, 2007.

14. Postgate A, Saunders B, Tjandra J, et al: Argon plasma coagulation in chronic radiation proctitis. Endoscopy 39: 361-365, 2007.

15. B Prost, G Poncet, J Scoazec, et al: Unusual complications of argon plasma coagulation. Gastrointest Endosc 59: 929-932, 2004.

16. Manner H, Plum N, Pech O, Ell C and Enderle MD: Colon explosion during argon plasma coagulation. Gastrointest Endosc 67: 1123-1127, 2008.

17. ASGE Technology Committee; Mamula P, Adler DG, Conway JD, et al: Colonoscopy preparation. Gastrointest Endosc 69: 1201-1209, 2009. 